www.jmscr.igmpublication.org

Impact Factor (SJIF): 6.379

Index Copernicus Value: 71.58

ISSN (e)-2347-176x ISSN (p) 2455-0450

crossref DOI: https://dx.doi.org/10.18535/jmscr/v6i6.126

Journal Of Medical Science And Clinical Research

\title{
Comparison of Exercises on two Unstable Surfaces for Balance and Gait Re- education in Patients with Diabetic Peripheral Neuropathy
}

\author{
Authors \\ Sowjanya Maruboyina ${ }^{1}$, Sanjeev Attry ${ }^{2}$, B Kusuma Kumari ${ }^{3}$, M Kranthi Kumar ${ }^{1}$ \\ Asha Srirama ${ }^{1}$ \\ ${ }^{1}$ Department of Neuro Physiotherapy, DDCOP, DDMS (AMS), Hyderabad, India \\ ${ }^{2}$ Department of Neuro Surgery, NIMS University, Jaipur, Rajasthan, India \\ ${ }^{3}$ Professor, Department of Physiology, MRIMS, Hyderabad, India \\ Corresponding Author \\ Sowjanya Maruboyina \\ Department of Neuro Physiotherapy, DDCOP, AMS, Hyderabad-500044, India \\ Email: soujimpt@gmail.com
}

\begin{abstract}
Background and Purpose: The incidence of diabetes is increasing rapidly in India, so as the complications are. The most significant complication is peripheral neuropathy which leads to weakness of muscles and lack of protective sensation in the foot because of demyelination of sensory and motor nerves. In this context patient will lose balance, feel difficulty while walking and may fall. So balance and gait reeducation plays a vital role to improve functional ability, postural control and to reduce falls. Till date many studies have been done to improve balance by using unstable surfaces. Comparison of two unstable surfaces is still lacking. So this study is intended to know whether wobble board is best or stability disc to improve balance in diabetic individuals.

Materials and Methods: 30 participants with diabetic neuropathy were randomly assigned into two groups; group $A(n=15)$ underwent exercises on wobble board and group $B(n=15)$ received exercises on stability disc for 30 min for 8 weeks. Pre and post intervention balance was assessed by Berg balance sale and gait was assessed by TUG.

Results: Results of Berg Balance Scale were analysed using non parametric tests and TUG scores were analysed using $t$ tests. The observed differences of values were tested with the $Z$ at $95 \%$ level of significance $(p<0.05)$.

Conclusion: Both groups have showed good upshots in recovery after the study. The subjects who were trained on stability disc showed substantial improvement when compared to subjects trained on wobble board $(p<0.05)$. Hence we conclude that stability disc is more effective than wobble board to improve balance in diabetic neuropathy patients.
\end{abstract}

Keywords: Diabetic neuropathy, Balance, Gait, Wobble board, Stability disc.

\section{Introduction}

Diabetes mellitus is becoming a crucial health confront to the entire globe. The unsurpassed financial growth and rapid urbanization has led to hike in the non-communicable diseases like diabetes and cardiovascular diseases. In India, the prevalence of diabetes is escalating at an alarming rate from 
31.7 million in 2000 to 79.4 million in $2030 .^{[1]}$ In 2000, India (31.7 million) is leading the entire world with utmost number of diabetic population followed by China (20.8 million) and the United States (17.7 million). ${ }^{[2]}$ Every fifth diabetic in the world is an Indian. ${ }^{[3]}$

Nevertheless, diabetic neuropathy (DN) is a widespread disorder which is defined as signs and symptoms of peripheral nerve dysfunction in a patient with diabetes mellitus (DM) in whom other causes of peripheral nerve dysfunction have been excluded. $^{[4]}$ It's prevalence varies from 13 to $68 \%$. $^{[5]}$ Among all types, sensory motor distal symmetric poly neuropathy is the wide spread one. ${ }^{[6]}$ Prolonged exposure to chronic hyperglycemia decides the severity of neuropathy. ${ }^{[7,8]}$ Sensory symptoms occur first in glove and stocking distribution and motor signs appear later. ${ }^{[4]}$ Decreased sensory perception in the feet may cause plantar ulcers, balance impairment, increased dependence in daily activities and falls. ${ }^{[9]}$

Compromise in sensory function in diabetic neuropathy leads to instability during stance and gait. ${ }^{[10]}$ The vestibular, visual, and proprioceptive sensations are majorly contributed for maintaining normal human posture. Postural instability in neuropathy is accredited to not having accurate proprioceptive feedback from the lower extremities. Neuropathic individuals reported 15 times higher rate of injuries during gait and were feeling less safe during unanticipated situations. ${ }^{[11]}$ Deprived balance can be attributed to impaired proprioception, movement-strategy dysfunction, anatomical and biomechanical disorders. Thus, increases the impact of micro traumas and wounds. ${ }^{[12]}$

Normal gait demands well-coordinated effort from various physiological systems. Since diabetes causes impairment of multiple organ subsystems, consequently the walking is altered. These individuals walk 20-30\% slower on par with the age matched healthy individuals. ${ }^{[13]}$ The gait alterations include reduced cadence, decreased gait velocity, shorter stride length, increased stance time. Uneven surfaces are more challenging for these patients. ${ }^{[5]}$
Treatment interventions emphasize on balance training and gait in diabetic neuropathy are abundant like Progressive Biodex Stability System, Rocker/Wobble-board Training, Gait and Balance exercises with function orientated strengthening, Whole Body Vibration etc. ${ }^{[14]}$ Training on unstable surface (swiss ball, bosu ball, wobble board, stability trainers) is more demanding and inspiring for the patients. Literature on comparing the unstable surfaces is flimsy. So In this study we compared exercises on wobble board versus stability disc to improve balance and gait in diabetic neuropathy patients.

\section{Methodology}

Patients of type 2 diabetes who matches the inclusion criteria of 4-8years of diabetes duration , both genders, strength of lower limb muscles not less than grade 3 by manual muscle testing, having moderate neuropathy on TORANTO SCALE(9-11), Berg balance scale score between 35-45, Timed up and Go score- not less than $15 \mathrm{sec}$ were enrolled. The exclusion criteria were; subjects having plantar ulcers and foot problems, any vestibular disorders, history of any orthopedic and neurological complications, peripheral vascular complications, any hearing and visual deficiencies.

\section{Procedure}

The selected 30 patients with described criteria were randomly allocated into two groups, Group-A and Group-B of 15 respectively. Informed consent was taken from those who agreed to participate in the study, clearly explained about the procedure and base line values were taken using Berg balance scale, Timed up and go test.

All the patients were treated with conventional therapy for $30 \mathrm{~min}$. In addition, participants in group A were given wobble board exercises for $15 \mathrm{~min}$ and individuals in group B received stability disc exercises, for 8 weeks, 3sessions a week. Conventional exercises included: Relaxed deep breathing exercises, range of motion exercises for bilateral ankle joints, sit to stand, standing weight shifts, heel standing, toe standing, reaching 


\section{JMSCR Vol||06||Issue||06||Page 752-756||June}

activities, single limb stance, ramp walking, tandem walking, stair climbing and spot marching .

Exercises on wobble board (Group A): Participants were instructed to do standing and balancing on wobble board, move the board forward and backward(grasp a chair for support if desired), then move side to side, rotate the wobble board round so that the edge of the board is in contact with floor, revolve the wobble board round without allowing the edge of the board to touch the floor, do small knee bends, gradually bend knees further into a squat, reach both arms out in front of them, rotate their upper body around slowly from side to side. All exercises were repeated with closed eyes.

\section{Exercises on stability disc (Group B): Subjects} were asked to do Standing and balancing on the stability disc, Bipedal heel rise, single limb stance, hip flexion balancing on one leg and keep the other hip at 90 degree flexion, Hip extension balance on one leg extend the other leg behind the body, Knee bending: balance on one leg bend the other leg to keep the knee up to 90 degree flexion and repeat all the exercises with other leg. ${ }^{[15]}$

\section{Results}

After completion of 8 weeks the scores of Berg Balance Scale, inter group results are compared by Mann-Whitney U Test and intra group results are done by Wilcoxon Signed Rank test.TUG scores were analysed by $\mathrm{t}$ test. Both groups have shown improvement in the scores of the two outcome measures. However when two groups were compared more improvement is seen in Group B.

Table 1: Berg Balance Scale Score in Group A and Group B

\begin{tabular}{|l|c|c|c|c|c|}
\hline & Group & $\mathbf{N}$ & Mean & $\begin{array}{c}\text { Std. } \\
\text { Deviation }\end{array}$ & $\begin{array}{c}\text { Std. Error } \\
\text { Mean }\end{array}$ \\
\hline \multirow{2}{*}{$\begin{array}{l}\text { BBS_Pr } \\
\text { e }\end{array}$} & Group A & 15 & 39.6000 & 3.71868 & .96016 \\
\cline { 2 - 6 } & Group B & 15 & 39.7333 & 3.51460 & .90746 \\
\hline \multirow{2}{*}{ BBS_Pos } & Group A & 15 & 41.7333 & 3.86313 & .99746 \\
\cline { 2 - 6 } & Group B & 15 & 44.9333 & 3.97252 & 1.02570 \\
\hline
\end{tabular}

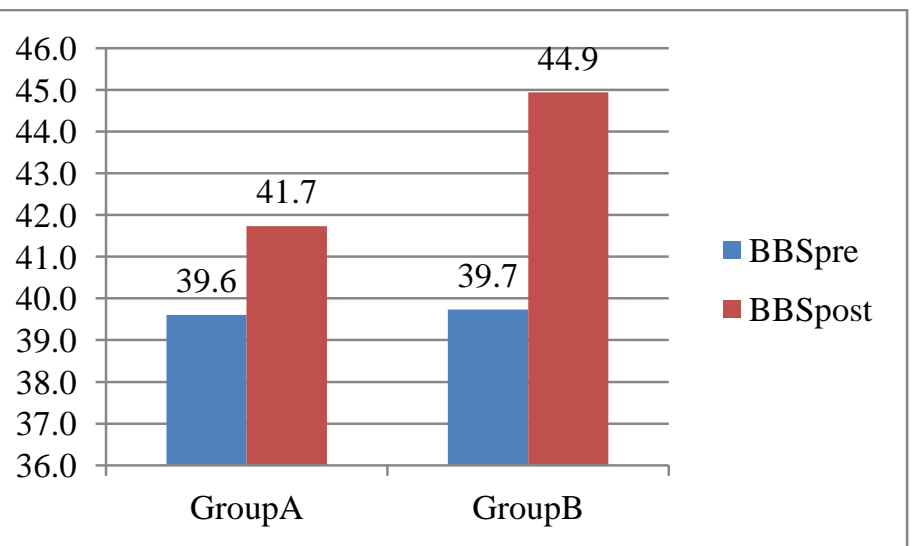

Table 2: TUG Score in Group A and Group B

\begin{tabular}{|l|c|c|c|c|c|}
\hline & Group & $\mathbf{N}$ & Mean & $\begin{array}{c}\text { Std. } \\
\text { Deviation }\end{array}$ & $\begin{array}{c}\text { Std. } \\
\text { Error } \\
\text { Mean }\end{array}$ \\
\hline TUG pre & Group A & 15 & 22.4000 & 1.50238 & .38791 \\
\cline { 2 - 6 } & Group B & 15 & 22.4667 & 1.35576 & .35006 \\
\hline \multirow{2}{*}{ TUG post } & Group A & 15 & 17.6000 & 1.54919 & .40000 \\
\cline { 2 - 6 } & Group B & 15 & 15.7333 & .96115 & .24817 \\
\hline
\end{tabular}

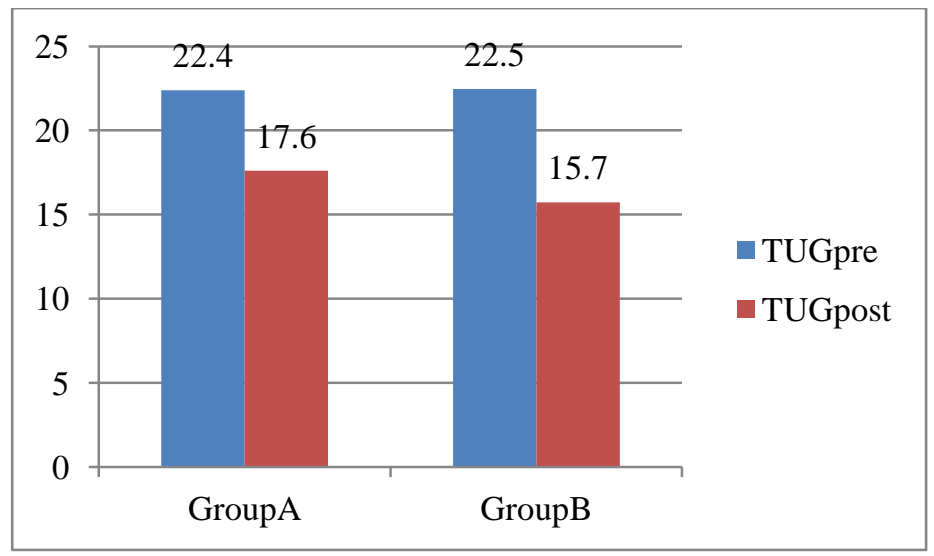

\section{Discussion}

In standing Somatosensory function contributes majorly around $60-75 \%$ for the postural control. ${ }^{[16]}$ The sensory receptors in the sole of feet are mainly concerned with exteroceptive skills like estimation of the texture and quality of the supportive surface. This cutaneous input provides information regarding the properties of the support surface. ${ }^{[17]}$

In neuropathic individuals decline in the function of somatosensory system leads to inaccurate proprioceptive information from the lower extremities to higher centres. In due course this makes the patients vulnerable to postural instability, falls and dependence in the functional abilities. ${ }^{[1]}$ The results of present study proclaim that proprioceptive training is effective for improving balance and gait in DPN patients as all 30 
individuals have shown intensification in the scores of BBS and TUG. These findings are consistent with the studies done by Irshad Ahmad et al., 2017, Mohammad Akbari et al, 2012, Abeer El-Wishy et al, 2012 who proved that diabetic patients benefit from balance training. In our study improvement is seen in patients treated with wobble board, these results are supported by Nizar Abdul Majeed Kutty et al, 2013, who explained that while standing on wobbly surface the visual and vestibular systems will become vital to stabilize the body as the proprioceptive inputs are decreased when compared to stable surface. Lower levels of nervous system uses peripheral inputs for automatic postural responses and higher levels will use it to build up internal representations of the self in space for the production of anticipatory postural adjustments and voluntary movements. ${ }^{[13]}$

Improvement seen in group B has been coinciding with previous studies done by M.S Ajimsha et al, 2011, Jyoti; Karol et al, 2016, have also emphasized the positive effects of balance training exercises on stability trainer, they proposed that, sensory inputs were manipulated by altering the support surface additionally proprioceptive training also augment firing from the cutaneous receptors of the feet and from mechanoreceptors of the muscle during cocontraction produced by the swaying movement. ${ }^{[11,14,18]}$ When we stand on stability disc the stimulus applied to the cutaneous receptors of the sole is keep on changing. This will stop adaptation of the receptors leads to continuous firing and transmission of impulses to higher centres. ${ }^{[19]}$ Future research may focus on more number of patients, long term follow up of the results with quantitative analysis of balance.

\section{Conclusion}

The results for outcome measures provide a strong evidence which conclude that both devices are useful in improving Balance and Gait but stability disc exercises are proven to be more significant and effective approach in improving balance and gait in diabetic neuropathy patients than wobble board exercises.

\section{Acknowledgement}

We acknowledge the support given by Dr. Chitturi Bhujanga Rao for providing insightful comments.

\section{References}

1. S. R. Mehta, A. S.Kashyap, S. Das "Diabetes Mellitus in India: The Modern Scourge" MJAFI, Vol. 65, No. 1, 2009.

2. S. A.Kaveeshwar, J. Cornwall, "The current state of diabetes mellitus in India" Australasian Medical Journal vol. 7, No. 1, pp. 45-48, 2014.

3. S. R Joshi, R. M Parikh, "India - Diabetes Capital of the World: Now Heading Towards Hypertension” JAPI, Vol. 55, pp323-324,May, 2007.

4. V.Bansal, J.Kalita, U. K.Misra, “ Diabetic neuropathy” Postgrad Med J.,vol- 82, pp. 95-100, jun, 2006;

5. L. Allet, S. Armand, R. A. de Bie, A. Golay, D. Monnin, K. Aminian, J. B. Staal, E. D. de Bruin, "The gait and balance of patients with diabetes can be improved: a randomised controlled trial'Diabetologia,vol-53, pp. 458-466,nov, 2010.

6. J.M.A.Boulton, A. I. Vinik, , J. C. Arezzo, V. Bril, E. L. Feldman, R. Freeman, R. A. Malik, R. E. Maser, J. M. Sosenko, D. Ziegler, Diabetic Neuropathies, Diabetes Care, vol. 28, no. 4, Apr. 2005.

7. J. A. Tracy, P. J. B. Dyck, "The Spectrum of Diabetic Neuropathies" Phys Med Rehabil Clin N Am.; vol. 19, no.1, pp-1-v.Feb. 2008.

8. M. U.Nisar, A.Asad, A.Waqas, N. Ali, A.Nisar, M.Qayyum, H. Maryam, M.Javaid, M.Jamil,"Association of Diabetic Neuropathy with Duration of Type 2 Diabetes and Glycemic Control" Cureus vol. 7, no. 8, pp. e302, Dec 2015.

9. M.Akbari, H.Jafari, A.Moshashaee, B. Forugh, "Do diabetic neuropathy patients benefit from balance training?" JRRD vol. 49, no. 2, pp.333-338, Nov 2012.

10. A.Nardone, M.Godi, A.Artuso, M.
Schieppati, "Balance Rehabilitation by 
moving platform and exercises in patients with neuropathy or vestibular deficit" Arch Phys Med Rehabil,vol. 91,pp- 1869-1877, Dec. 2010

11. D.Lafond, H.Corriveau, F. Prince, "Postural control mechanisms during quiet standing in patients with diabetic sensory neuropathy" Diabetes Care, vol. 27, no.1,pp-173-178, jan. 2004.

12. A. El-Wishy, E.Elsayed, "Effect of proprioceptive training program on balance in patients with diabetic neuropathy: A controlled randomized study" Bull. Fac. Ph. Th. Cairo Univ., vol. 17, no. 2, pp-1-8, Jul. 2012.

13. N. A. M.Kutty, N. A. L. Majida,"Effects of multisensory training on balance and gait in persons with type 2 diabetes"A Randomised Controlled Trial, vol. 24, No. 2, pp-79-91, 2013.

14. I. Ahmad, E.Hussain, D.Singla, S. Verma, K. Ali, "Balance training in diabetic peripheral neuropathy: A narrative review" JSM Diabetol Manag, vol. 2, no. 1, 1002, jan 2017.

15. M.S. Ajimsha, J.K. Paul, S. Chithra, "Efficacy of stability trainer in improving balance in type II diabetic patients with distal sensory neuropathy" Journal of Diabetology, 1:6, Oct. 2011.

16. F. B. Horak, R. Dickstein, R. J. Peterka, "Diabetic neuropathy and surface swayreferencing disrupt somatosensory information for postural stability in stance" Somatosensory \& Motor Research, vol. 19, no. 4, pp. 316-326, 2002.

17. C. Maurera, T. Mergnera, B. Bolhab, F. Hlavackab, "Human balance control during cutaneous stimulation of the plantar soles" Neuroscience Letters, vol. 302, pp. 45-48, feb 2001

18. K. Jyoti, J. Gauri,Vinay, "A study of the effect of stability trainer on dynamic balance in distal sensory diabetic neuropathy" JESP vol. 12, no. 1, pp. 94-98, jan 2016:
19. Arthur c Guyton,"Text book of medical physiology" eleventh edition. Chapter 46. pp. 574-576. Saunders,Elsevier publishers, 2007. 